\title{
Dermatoses gestacionais: a propósito de um caso clínico
}

Joana F Almeida*, Maria João Teles*

\section{RESUMO}

Introdução: Definem-se Dermatoses Gestacionais como doenças de pele que surgem apenas em grávidas ou puérperas. Estas entidades diferem quanto às manifestações clínicas, mas principalmente no que se refere ao curso clínico, prognóstico e tratamento mais adequado. Torna-se necessário reconhecê-las e diagnosticá-las para orientar a grávida ou a puérpera da forma mais adequada. O objetivo deste trabalho é relatar um caso clínico de Placas e Pápulas Urticariformes Pruriginosas da Gravidez, salientando a importância da sua correta identificação e orientação, contribuindo para o bem-estar materno-fetal.

Descrição do Caso: Utente do sexo feminino, 17 anos de idade, etnia cigana, solteira, IGOP. Em 25 de Julho de 2011 recorreu ao serviço de urgência de Pediatria por eritema e prurido generalizados e gestação de 37 semanas. A gravidez tinha sido vigiada em Medicina Privada e sem intercorrências até às 36 semanas, altura em que surgiu um eritema maculopapular generalizado, de instalação gradual e muito pruriginoso, sem repercussão no bem-estar fetal. Foi internada no serviço de Obstetrícia para monitorização fetal, investigação e tratamento sintomático. Dez dias mais tarde ocorreu o parto eutócico, às 38 semanas e 3 dias de idade gestacional, de nado vivo saudável e sem intercorrências. Em menos de 24 horas pós-parto, as lesões cutâneas tinham regredido quase completamente.

Comentário: Com este trabalho pretende-se enfatizar a importância do diagnóstico e orientação corretos e atempados de grávidas ou puérperas com manifestações cutâneas. Apesar de não se tratarem de doenças muito frequentes, surgem em mulheres saudáveis, sem fatores de risco conhecidos, provavelmente vigiadas nos Cuidados de Saúde Primários.

Palavras-chave: gravidez; doenças da pele; Medicina Geral e Familiar.

\section{INTRODUÇÃO}

A s Dermatoses Gestacionais são doenças de pele que ocorrem exclusivamente durante a gravidez ou puerpério. Neste grupo de patologias incluem-se: Placas e Pápulas Urticariformes Pruriginosas da Gravidez (PUPP), Penfigóide Gestacional, Erupção atópica da Gravidez, Psoríase Pustulosa da Gestação e Colestase Intrahepática da

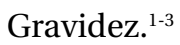

Algumas destas entidades clínicas apresentam manifestações clínicas semelhantes, pelo que devem ser cuidadosamente avaliadas (tabela I), sendo muito importante reconhecê-las porque diferem no curso, prognóstico e tratamento, variando desde aquelas cujo diagnóstico é apenas clínico, o tratamento sintomático, com regressão espontânea, sem afetar o bem-estar fetal, a outras cujo diagnóstico requer biópsia cutânea, o tra-

*Médica Interna de Medicina Geral e Familiar, USF Camélias, ACES Grande Porto VII/Gaia, Portugal tamento é dirigido e o feto deve ser monitorizado porque o seu bem-estar está comprometido e o prognóstico é reservado. ${ }^{2}$

Saliente-se a importância de distinguir Penfigóide Gestacional e Psoríase Pustulosa da Gestação das outras, por estas serem as que necessitam de tratamento efetivo e de internamento para monitorização fetal..$^{3-4}$

\section{DESCRIÇÃO DO CASO}

TM, sexo feminino, 17 anos, solteira, raça cigana, feirante. Pertence a uma família alargada, sendo o agregado familiar constituído pela própria, o noivo, os pais do noivo e dois irmãos do noivo, de classe baixa de Graffar. Sem antecedentes pessoais ou familiares de relevantes.

Primigesta, gestação de 37 semanas, não planeada, mas desejada, vigiada em obstetra privado, sem qualquer intercorrência de relevo.

Em 25 de julho de 2011 recorreu ao serviço de urgência de pediatria por eritema maculopapular gene- 
ralizado, que poupava as palmas, plantas dos pés, face e couro cabeludo, mas atingia todas as outras regiões do corpo, sendo mais acentuado no tórax, abdómen, região posterior dos antebraços e coxas, acompanhado de prurido muito intenso, com algum alívio após aplicação de água termal, com cerca de uma semana de evolução. Estas lesões cutâneas foram surgindo gradualmente, atingindo de início o abdómen, depois os membros inferiores $\mathrm{e}$ de seguida o tórax e membros superiores. Depois de questionada, a grávida referiu ter notado inicialmente o aparecimento de algumas vesículas, a maior na região periumbilical. Não foram detetados outros sintomas acompanhantes.

Sem contexto epidemiológico de doença. A grávida nega ingestão de alimentos ou medicamentos de novo, nega alteração dos produtos de cosméticos e de higiene pessoal, contacto com animais e viagens recentes.

No dia anterior tinha recorrido ao serviço de urgência de obstetrícia pelas mesmas queixas. Nessa altura realizou: fita-teste de urina, que estava sem alterações; cardiotocografia, com traçado variável e reativo e contrações uterinas irregulares; ecografia fetal, que revelou apresentação cefálica, boa vitalidade e líquido amniótico normal; estudo laboratorial (hemograma, bioquímica com enzimas hepáticas), cujos valores se encontravam dentro dos parâmetros da normalidade.

Ao exame objetivo, no serviço de urgência de pediatria, apresentava razoável estado geral, mucosas coradas e hidratadas, estava apirética, eupneica e normotensa. Encontrava-se muito incomodada com o prurido e muito queixosa.

O tegumento cutâneo apresentava eritema maculopapular quase generalizado, sem vesículas, que poupava a face, couro cabeludo, palmas das mãos e plantas dos pés. Eram também visíveis lesões de coceira, sem sinais de infeção.

A auscultação cardíaca era normal: sons respiratórios bilaterais e simétricos, sem ruídos adventícios. O abdómen estava distendido pela gravidez. Não apresentava outras alterações de relevo ao exame físico.

Foi decidido internamento no serviço de obstetrícia para monitorização fetal, tratamento sintomático com betametasona tópica e hidroxizina oral e investigação clínica. Para afastar a hipótese diagnóstica de Colestase Intrahepática da Gravidez foi feito doseamento das enzimas hepáticas e bilirrubinas que se revelou normal; dosearam-se também os níveis de anticorpos antimembrana basal da pele, antisubstância intercelular e anti BP180 que foram todos negativos.

Perante estes resultados analíticos e estando afastadas as hipóteses diagnósticas que necessitariam de acompanhamento da grávida em internamento, foi assumido o diagnóstico de PUPP e dada alta para o domicílio em 27 de julho.

Em 4 de agosto foi readmitida já em trabalho de parto sendo, que às 38 semanas e 3 dias de idade gestacio- 
nal, ocorreu o parto, eutócico, de nado vivo, aparentemente saudável e sem intercorrências.

Em menos de 24 horas pós-parto, as lesões cutâneas tinham regredido quase completamente.

\section{COMENTÁRIO}

A entidade clínica PUPP da Gravidez (também designada Erupção Polimórfica da Gravidez ou Eritema tóxico da gravidez ou Rash de Bourne ou Dermatose IgM linear da gravidez) é a dermatose gestacional mais comum, com uma incidência que varia entre $1 / 160$ a $1 / 300$ grávidas, $3 / 4$ das quais nulíparas. ${ }^{5}$ Geralmente surge no terceiro trimestre da gestação, mas pode também aparecer de novo no puerpério. O diagnóstico da PUPP é clínico, pelo que importa saber que inicialmente surgem lesões cutâneas papulares eritematosas, abdominais, que poupam o umbigo e que, posteriormente, coalescem para formar placas urticariformes. Estas lesões poupam a face, as palmas das mãos e as plantas dos pés. ${ }^{6}$

Existem três subtipos clínicos de PUPP: ${ }^{7}$

- subtipo um: apresentação clássica (placas e pápulas sem atingimento da face, palmas e plantas);

- subtipo dois: maculopapular (placas eritematosas com sobreposição de pápulas e vesículas);

- subtipo três: características dos subtipos 1 e 2 .

O tratamento da PUPP é sintomático e inclui corticóides tópicos e antihistamínicos orais. Em casos selecionados, os corticóides sistémicos têm indicação. ${ }^{5}$

Esta dermatose gestacional não comporta riscos para a mãe ou para o feto, não estando por isso indicado acelerar o trabalho de parto. ${ }^{5}$

Outras doenças mais graves fazem diagnóstico diferencial com PUPP, pelo que é preciso manter elevado grau de suspeição diagnóstica: Penfigóide Gestacional, Eritema Multiforme, reações alérgicas a fármacos, Escabiose. $^{7}$

No caso clínico apresentado e na altura de observação da grávida no serviço de urgência, os diagnósticos diferenciais que se colocaram, devido às características das lesões cutâneas, foram PUPP e Penfigóide Gestacional.

O Penfigóide Gestacional é muito mais raro que a PUPP (incidência de $1 / 1.700$ a 1/50.000 grávidas) e está associado a risco fetal por insuficiência placentar. Nesta patologia, o prurido precede as lesões, surgem pla- cas urticariformes no tronco ou pápulas em volta do umbigo e depois vesículas que coalescem para formar bolhas. As lesões cutâneas atingem as palmas das mãos e plantas dos pés, poupando apenas as mucosas e a face. $^{8}$

A etiologia do Penfigóide Gestacional está relacionada com o anticorpo IgG BP180 que se liga ao antigénio BP-AG2, que é uma glicoproteína transcelular no hemidesmossoma, afetando a substância intercelular. ${ }^{8}$

Tendo persistido a dúvida diagnóstica durante a permanência da grávida no serviço de urgência, optou-se pelo internamento no serviço de obstetrícia, com monitorização fetal e doseamento de anticorpos antimembrana basal da pele, antisubstância intercelular e anti BP180 que foram negativos. Este dado e a ausência de intercorrências durante o internamento permitiram, com segurança, assumir o diagnóstico de PUPP e dar alta para o domicílio no terceiro dia de internamento, mantendo a habitual vigilância da gravidez em ambulatório.

Da investigação clínica deste caso fez parte o doseamento de enzimas hepáticas, porque a Colestase Intrahepática da Gravidez pode apresentar-se com lesões cutâneas devido ao prurido intenso que provoca. É muito importante excluir este diagnóstico pela orientação terapêutica completamente distinta que seria necessária caso se confirmasse. ${ }^{9}$

Este trabalho pretende enfatizar a importância do diagnóstico correto e atempado de grávidas ou puérperas com lesões cutâneas. É importante reconhecer e distinguir, entre todas as dermatoses gestacionais, aquelas entidades benignas das outras que podem comprometer o bem-estar materno- fetal: Penfigóide Gestacional e Psoríase Pustulosa da Gestação. Estas últimas implicam monitorização fetal e tratamento efetivo e podem tornar-se extremamente sérias e ameaçadoras de vida.

Apesar das Dermatoses Gestacionais não serem doenças muito prevalentes, surgem em mulheres saudáveis, cujas gravidezes são muito provavelmente vigiadas nos Cuidados de Saúde Primários, pelo que o Médico de Família será o primeiro médico a contactar com estes casos e deve saber reconhecer e orientá-los adequadamente.

Assim, perante as queixas de prurido ou lesões cutâneas numa grávida, o Médico de Família deve excluir 
com segurança os diagnósticos de Colestase Intrahepática da Gravidez, Penfigóide Gestacional e Psoríase Pustulosa da Gestação. A exclusão destas entidades clínicas necessita muitas vezes de exames complementares de diagnóstico não disponíveis nos Cuidados de Saúde Primários, pelo que, perante uma suspeita, deve ser efetuada referenciação a um serviço de urgência de Obstetrícia.

Uma vez excluídas estas três entidades clínicas, o Médico de Família pode manter a vigilância habitual da grávida em ambulatório e se necessário instituir tratamento sintomático.

\section{REFERÊNCIAS BIBLIOGRÁFICAS}

1. Roth MM. Pregnancy dermatoses: diagnosis, management, and controversies. Am J Clin Dermatol. 2011;12(1):25-41.

2. Kroumpouzos G, Cohen LM. Specific dermatoses of pregnancy: an evidence-based systematic review. Am J Obstet Gynecol. 2003;188(4): 1083-92.

3. Ahmadi S, Powell FC. Pruritic urticarial papules and plaques of pregnancy: current status. Australas J Dermatol. 2005;46(2):53-8.

4. Ogilvie P, Trautmann A, Dummer W, Rose C, Brocker EB, Zillikens D. [Pemphigoid gestationis without blisters]. Hautarzt. 2000;51(1):25-30. German

5. Matz H, Orion E, Wolf R. Pruritic urticarial papules and plaques of preg- nancy: polymorphic eruption of pregnancy (PUPPP). Clin Dermatol. 2006;24(2):105-8.

6. Aronson IK, Bond S, Fiedler VC, Vomvouras S, Gruber D, Ruiz C. Pruritic urticarial papules and plaques of pregnancy: clinical and immunopathologic observations in 57 patients. J Am Acad Dermatol. 1998;39(6): 933-9.

7. Thurston A, Grau RH.An update on the dermatoses of pregnancy. J Okla State Med Assoc. 2008;101(1):7-11.

8. Al-Fouzan AW, Galadari I, Oumeish I, Oumeish OY. Herpes gestationis (Pemphigoid gestationis). Clin Dermatol. 2006;24(2):109-12.

9. Medina Lomelí JM, Jáuregui Meléndrez RA, Medina Castro N, Medina Castro D. Colestasis intrahepática del embarazo: una revisión [Intrahepatic cholestasis of pregnancy: review]. Ginecol Obstet Mex. 2012;80 (4):285-94. Spanish

\section{CONFLITOS DE INTERESSE}

As autoras declaram não possuir quaisquer conflitos de interesse.

\author{
ENDEREÇO PARA CORRESPONDÊNCIA \\ Joana F. Almeida \\ Unidade de Saúde Familiar Camélias \\ Rua João de Deus, 98/106 \\ 4410-182 Vila Nova de Gaia \\ E-mail: joanamfalmeida@gmail.com
}

Recebido em 20-08-2013

Aceite para publicação em 11-06-2014

\section{ABSTRACT}

\section{DERMATOSIS OF PREGNANCY: A CASE REPORT}

Background: Dermatoses of pregnancy are skin diseases that arise in pregnant or postpartum women. These entities differ in their clinical manifestations and in their course, prognosis and treatment. It is necessary to diagnose them for appropriate management. The aim of this report is to describe a case of pruritic urticarial papules and plaques of pregnancy, emphasizing the importance of correct identification and management for the well-being of the mother and the fetus.

Case description: The patient is a 17 year-old single primagravid female, of Rom origin, who was previously well. She presented to a pediatric emergency room complaining of generalized erythema and pruritus at 37 weeks. The pregnancy was uneventful until the 36th week, when she noted the gradual appearance of a generalized and itchy maculopapular rash. She was admitted to the department of obstetrics, for fetal monitoring, investigation and symptomatic treatment. Ten days later she gave birth to a healthy baby at 38 weeks gestational age. Less than 24 hours postpartum, the skin lesions and itching had almost completely resolved.

Commentary: This case report emphasizes the importance of the diagnosis and timely management of pregnant and postpartum women with skin lesions. Dermatoses of pregnancy are uncommon and may appear in healthy women without known risk factors.

Keywords: pregnancy; skin diseases; Family Practice. 